\title{
Shared genetic influences do not explain the association between parent-offspring relationship quality and offspring internalizing problems: results from a Children-of-Twins study
}

\author{
L. J. Hannigan ${ }^{1}$, F. V. Rijsdijk1 ${ }^{1}$, J. M. Ganiban ${ }^{2}$, D. Reiss ${ }^{3}$, E. L. Spotts ${ }^{4}$, J. M. Neiderhiser ${ }^{5}$, \\ P. Lichtenstein ${ }^{6}$, T. A. McAdams ${ }^{1 *}+$ and T. C. Eley ${ }^{1}+$ \\ ${ }^{1}$ Institute of Psychiatry, Psychology \& Neuroscience, MRC Social, Genetic \& Developmental Psychiatry Centre, King's College London, London, UK \\ ${ }^{2}$ Department of Psychology, The George Washington University, Washington, DC, USA \\ ${ }^{3}$ Yale Child Study Center, New Haven, CT, USA \\ ${ }^{4}$ Office of Behavioral and Social Science Research, NIH, Bethesda, MD, USA \\ ${ }^{5}$ Department of Psychology, The Pennsylvania State University, State College, PA, USA \\ ${ }^{6}$ Department of Medical Epidemiology and Biostatistics, Karolinksa Institutet, Stockholm, Sweden
}

Background. Associations between parenting and child outcomes are often interpreted as reflecting causal, social influences. However, such associations may be confounded by genes common to children and their biological parents. To the extent that these shared genes influence behaviours in both generations, a passive genetic mechanism may explain links between them. Here we aim to quantify the relative importance of passive genetic $v$. social mechanisms in the intergenerational association between parent-offspring relationship quality and offspring internalizing problems in adolescence.

Methods. We used a Children-of-Twins (CoT) design with data from the parent-based Twin and Offspring Study of Sweden (TOSS) sample [909 adult twin pairs and their offspring; offspring mean age 15.75 (2.42) years], and the child-based Swedish Twin Study of CHild and Adolescent Development (TCHAD) sample [1120 adolescent twin pairs; mean age 13.67 (0.47) years]. A composite of parent-report measures (closeness, conflict, disagreements, expressions of affection) indexed parent-offspring relationship quality in TOSS, and offspring self-reported internalizing symptoms were assessed using the Child Behavior Checklist (CBCL) in both samples.

Results. A social transmission mechanism explained the intergenerational association $[r=0.21(0.16-0.25)]$ in our best-fitting model. A passive genetic transmission pathway was not found to be significant, indicating that parental genetic influences on parent-offspring relationship quality and offspring genetic influences on their internalizing problems were non-overlapping.

Conclusion. These results indicate that this intergenerational association is a product of social interactions between children and parents, within which bidirectional effects are highly plausible. Results from genetically informative studies of parentingrelated effects should be used to help refine early parenting interventions aimed at reducing risk for psychopathology.

Received 28 February 2017; Revised 14 June 2017; Accepted 15 June 2017; First published online 26 July 2017

Key words: Behavioural genetics, children-of-twins, gene-environment correlation, internalizing problems, parent-child relationship.

Internalizing problems in childhood have been well established as predictors of risk for later mental health issues (Harrington et al. 1990; Kim-Cohen et al. 2003; Roza et al. 2003; Rutter et al. 2006). These problems, which include generalized symptoms of anxiety and

\footnotetext{
* Address for correspondence: T. A. McAdams, Ph.D., Institute of Psychiatry, Psychology \& Neuroscience, MRC Social, Genetic \& Developmental Psychiatry Centre, King's College London, London, UK.

(Email: tom.mcadams@kcl.ac.uk)

+ These authors are joint senior authors.
}

depressed mood, are moderately heritable [see reviews by Rice et al. 2002 (depression); Rapee et al. 2009 (anxiety)] and tend to emerge early in development (Kovacs \& Devlin, 1998; Kessler et al. 2005). As such, the possible role of parenting interactions in their aetiology has been investigated extensively, and associations have been shown with parental discipline (McKee et al. 2007; Laskey \& Cartwright-Hatton, 2009), parental overinvolvement (Hudson \& Rapee, 2001; Narusyte et al. 2008) and parental psychopathology (Connell \& Goodman, 2002; Goodman et al. 2011) among many others (see meta-analytic reviews by McLeod et al. 2007; Yap \& Jorm, 2015; Möller et al. 2016). 
Observed associations between parenting behaviours and children's internalizing problems are often interpreted, particularly in lay contexts, as reflecting causal, parent-to-child effects, mediated via social interactions and learning processes. However, this interpretation makes assumptions about both the direction of effects and, more fundamentally, the nature of the mechanism by which these effects are mediated. Longitudinal research can help to clarify the true direction of effects, but the nature of the association often remains confounded. In particular, this is because, while a social, environmental mechanism (within which effects may still be bidirectional) is one possibility, shared genes mean that associations between biologically related parents and children may result from a passive genetic mechanism (or passive gene-environment correlation; Plomin et al. 1977). Children receive their autosomal DNA from both parents in approximately equal proportions - resulting in considerable $(\approx 50 \%)$ overlap in their genes. With parents thus providing both environments and genes for their children, the mechanism underlying any given parent-offspring association cannot be assumed. Parenting interactions could be related to children's internalizing problems via the social interactions they share, but shared genes could plausibly underpin both. The coordinated use of different genetically sensitive designs is required to disentangle the roles played by these different mechanisms.

Genetically informative research designs have long provided an important tool for studying children's environmental exposures (Plomin et al. 1985, 1989; Plomin \& Bergeman, 1991; Braungart et al. 1992). In such designs, the estimation of genetic effects allows environmental sources of variation to be distinguished from those that are genetically confounded (Neiderhiser, 2001). Genetically informative research indicates that parents' behaviour towards their children is subject to influence from both parent's and children's genes (Neiderhiser et al. 2004, 2007; see reviews by Kendler \& Baker, 2007; Klahr \& Burt, 2014). When the objective is to estimate the extent to which an association incorporating both parent and child behaviours is affected by potential confounding by shared genes, the Children-of-Twins (CoT) design (D'Onofrio et al. 2003) is particularly useful (McAdams et al. 2014). In the CoT design, the genetically informative relationship (i.e. twinship) exists in the parent generation, with data collected from both twins and their respective offspring. The logic underlying the classical twin design is then applied to all genetic relationships within these families, to allow influences on both parent and child traits to be partitioned into genetic and environmental components. Moreover, the inclusion of differential intergenerational genetic relationships in the CoT design (an aunt in an identical twin family is more related to her nephew than an aunt in a nonidentical twin family) also allows associations between parent and child traits to be partitioned; into passive genetic transmission (due to genes shared across the generations) and social transmission mediated through parents' and children's interactions with one another (D'Onofrio et al. 2003; McAdams et al. 2014).

Associations between children's internalizing problems and parent characteristics have been relatively well studied using the CoT design. Primarily, these investigations have focused on associations between children's internalizing and analogous problems in the parent generation, such as anxiety and depression, finding that these associations appear to result from social, rather than passive genetic, mechanisms (Silberg et al. 2010; Singh \& D'Onofrio, 2011; Eley et al. 2015; McAdams et al. 2015; see McAdams et al. 2014 for a review). Relatively, fewer CoT studies have investigated associations between parenting and children's internalizing problems. Within the Twin and Offspring Study of Sweden (TOSS) sample used in the current study, an association between maternal emotional overinvolvement and offspring internalizing problems was found to be best explained by children's genetically influenced behaviour evoking a response from the mothers (Narusyte et al. 2008). A later study found evidence that associations between family conflict and offspring internalizing were largely unconfounded by shared genes shared across the generations (Schermerhorn et al. 2011). Similarly, the link between parental criticism and adolescent somatic symptoms was found to be free of confounding via a passive genetic mechanism (Horwitz et al. 2015). Finally, a recent analysis of the association between closeness and affection in the parent-child relationship and adolescent self-worth found similar results; the intergenerational association was not confounded by shared genes (McAdams et al. 2017).

While specific parenting behaviours such as these appear to have socially mediated links with children's internalizing problems, it bears consideration that these behaviours are unlikely to be experienced by children in the way that they are commonly measured: as discrete, clearly delineated behaviours. Instead, a conceptualization of parenting as a complex amalgam of multiple behaviours may better represent the overall quality of the parent-child relationship (Belsky, 1984; Darling \& Steinberg, 1993). This relationship, while influenced by specific parenting behaviours, is also shaped by the stable behavioural characteristics of both parents and children (Kendler et al. 1997; Kiff et al. 2011), reactive and situational responses (Miller et al. 1998; Metsäpelto et al. 2001; Critchley \& Sanson, 2006), perceptual tendencies (Reidler \& Swenson, 
2012; Hannigan et al. 2016a) and development-related change (Steinberg, 2000; Ludeke et al. 2013; Hannigan et al. 2016b). Further, the emotional valence of this relationship in a child's life is considerable, making it a particularly relevant context in which to examine the development of internalizing problems. Assessing multiple aspects of the parent-child relationship concurrently, including adaptive as well as maladaptive behaviours, may help to provide a more comprehensive picture of a developing child's experience within their home environment. To our knowledge, no previous study has done this in a CoT framework to investigate the aetiology of links between the parent-child relationship and internalizing behaviours.

\section{The current study}

In the current study, we apply the CoT design to data on parents' relationship with their adolescent offspring and offspring internalizing problems, with the aim of identifying the extent of passive genetic $v$. social effects in the association between them. Genetic and environmental influences on parent-offspring relationship quality are estimated by comparing the similarity of identical and non-identical adult twins (TOSS sample) in terms of their relationship with their adolescent children. Variance in offspring internalizing problems is similarly decomposed, by comparing the phenotypic similarity of cousins in identical and non-identical twin families (TOSS) and of child twins in a parallel sample (the Swedish Twin Study of CHild and Adolescent Development, TCHAD). The extent of passive genetic $v$. social transmission is estimated by comparing avuncular (aunt/uncle with niece/nephew) correlations between parent-offspring relationship quality and offspring internalizing in the families of the identical and nonidentical adult twins.

\section{Methods}

\section{Samples}

Twin and Offspring Study of Sweden (TOSS)

Data drawn from the TOSS sample, comprised 909 pairs of (same-sex) twins, their child and spouse. Twin parents in the study sample were $63 \%$ female, while their offspring were $48 \%$ female. The number of monozygotic (MZ) twins in the study sample was 765 (44.1\%); included dizygotic (DZ) twins numbered 969. The average age of twins was 44.87 years (S.D. = 4.86) and of their offspring was 15.75 years (S.D. = 2.42). The TOSS sample has been described in detail elsewhere (Neiderhiser \& Lichtenstein, 2008).
Swedish Twin Study of CHild and Adolescent Development (TCHAD)

Data drawn from TCHAD comprised 1120 adolescent twin pairs. Twins were $52 \%$ female, with an average age of 13.67 years (s.D. $=0.47$ ), while $895(40.2 \%)$ were MZ twins and 1334 were DZ twins. DZ twin pairs in this sample included opposite sex twin pairs (comprising 782 individuals). Full details of the TCHAD sample are provided in Lichtenstein et al. (2007).

In both studies, informed consent was obtained prior to individuals' participation and both the TOSS and TCHAD projects received ethical approval from the Institutional Review Boards of the home institutions concerned (Lichtenstein et al. 2007; Neiderhiser et al. 2007).

\section{Measures}

Parent-offspring relationship quality

A composite scale indexing the overall quality of the parent-offspring relationship was derived from both maternal and paternal reports on three parenting-related scales. We opted to use a composite score because of the breadth of the construct of interest - the parent-offspring relationship - and in order to make our coverage of this construct as comprehensive as possible. Scales were selected for inclusion in the composite because they specifically addressed facets of parent-offspring interactions that are relevant to child outcomes. Disagreements about rules and behaviour in the household were assessed using a 38-item Child Rearing Issues: Parent-Child Agreement scale (Hetherington \& Clingempeel, 1992). Parents reported on how often certain behavioural interactions occur with seven-point Likert scale responses to items such as 'How often have you not agreed with your child concerning if he/she uses alcohol?'. A 22-item Expressions of Affection scale (Hetherington \& Clingempeel, 1992) measured both the frequency of parents' expressions of affection towards their child and their engagement in behaviours, such as playing music together. A seven-point Likert scale was again used to record parents' responses, and scores on this variable were reversed for inclusion in the composite. Finally, the 27-item Parent-Child Relationship (PCR) questionnaire (Hetherington \& Clingempeel, 1992) was used to elicit parents' perceptions of the closeness (items reverse-scored) and conflict in their relationship with their children (e.g. 'How well do you and your child understand each other?'), via a five-point Likert scale.

Individual scale scores were standardized to give each an equal weight in the composite, with an overall mean taken (Cronbach's $\alpha=0.68$ ). This meant that the highest scores would represent the lowest quality 
parent-child relationships (characterized by high levels of disagreement and conflict and by low levels of expressed affection and closeness). Individuals were required to have some data available on at least two of the scales to receive a score on the composite and thus be included in the analyses. Composite scale scores approximated a normal distribution, and so standardized raw scores were used in the analyses. This approach of creating a composite score from multiple parenting measures reduces single-measure biases and has been used in previous analyses with similar data (Neiderhiser et al. 2004; Marceau et al. 2013).

\section{Internalizing problems}

Offspring internalizing problems were assessed using the Youth Self-Report version of the widely-used Child Behavior Checklist (CBCL; Achenbach \& Edelbrock, 1983; Achenbach, 1991) in both samples. Self-reports (rather than parent reports) of offspring internalizing problems were used to ensure that the decomposition of the intergenerational association was not confounded by rater-specific biases. The CBCL internalizing sub-scale indexes anxious/depressed behaviours, withdrawn behaviours and somatic complaints. Responses are given on a three-point scale. Scores on this measure were positively skewed in both samples, so were transformed using a Box-Cox transformation (Cox et al. 1964; Sakia, 1992) prior to analysis, which resulted in approximately normal distributions. Internal consistency for this scale was good in both TOSS (Cronbach's $\alpha=0.86$ ) and TCHAD (0.88).

\section{Genetic analysis}

The CoT design

The CoT design is an extension of the logic of the classical twin design (Rijsdijk \& Sham, 2002). Its power lies in the nature of the avuncular relationship between the child of a twin and their parent's co-twin (their aunt or uncle). In the case of MZ twin-pair parents, a child will share as much genetic material with his aunt or uncle as with his own parent; whereas when the parent and aunt/uncle of the child are DZ twins, the avuncular genetic correlations are half as strong (Fig. 1). If passive genetic transmission between the parenting and child outcome phenotypes is in effect, MZ avuncular phenotypic correlations will therefore be higher than DZ avuncular phenotypic correlations.

The full CoT model used in this study is shown in Fig. 2. Variance in the observed phenotypes is decomposed into genetic $(A)$, shared environmental $(C)$ and unique environmental $(E)$ influences. Passive genetic transmission is possible via the $A 1-A 1^{\prime}$ path, which is fixed at 0.5 to reflect the proportion of segregating genetic material shared, on average, by parents and children. Social transmission is possible via the central $p$ path, which, although conventionally drawn as a single-headed arrow from parent to child, includes bidirectional effects.

Data from a parallel child-based sample (TCHAD) were incorporated into the part of the CoT model estimating the genetic and environmental components of variance for offspring internalizing problems. This has two main advantages. The first is an increase in power to detect genetic effects in the offspring generation. In the CoT sample, cousins in MZ families share approximately $25 \%$ of their segregating genes, whereas those in DZ families share approximately $12.5 \%$. In a childbased sample, this ratio remains consistent with respect to genetic relatedness, but overall proportions of shared genes in the offspring generation are increased (e.g. $100 \%$ and $50 \%$ in MZ and DZ families), which increases statistical power. The second is that, in a CoT model based on a children-of-twins sample (e.g. TOSS) only, influences from the shared rearing environment cannot be estimated in the offspring generation, which consists of (non-cohabiting) cousins in MZ and DZ twin families. However, with the addition of data from a parallel childbased sample (TCHAD) wherein twin children do cohabit, this effect can be estimated (represented by 'C2' in Fig. 2). It should be noted that this strategy forms part of the Extended Children-of-Twins (ECoT) model (Narusyte et al. 2008), which combines children-of-twin and child-as-twin datasets in order to estimate bidirectional effects, but that our model is still specified as a standard CoT due to the unavailability of relevant parent-offspring relationship variables in the child-based sample, which is required for the ECoT specification.

\section{Results}

Correlations within and between parents and offspring in MZ and DZ families, respectively, are presented in Table 1. MZ twin correlations in the parent generation (in the TOSS sample only) exceeded DZ twin correlations (0.35 v. 0.19), indicating genetic influence on parent-offspring relationship quality. In the offspring generation, cross-cousin correlations in the TOSS sample were slightly larger in $\mathrm{MZ}$ families compared with DZ families (0.16 v. 0.10), as were cross-twin correlations in the child-based TCHAD sample (0.55 v. 0.27), which indicates some genetic influence on offspring internalizing problems. Parent-offspring correlations, which were constrained to be equal across zygosity groups as an assumption of the model, indicated a modest but significant intergenerational association (0.21). MZ avuncular correlations were not significantly different from DZ avuncular correlations $(0.07$ 


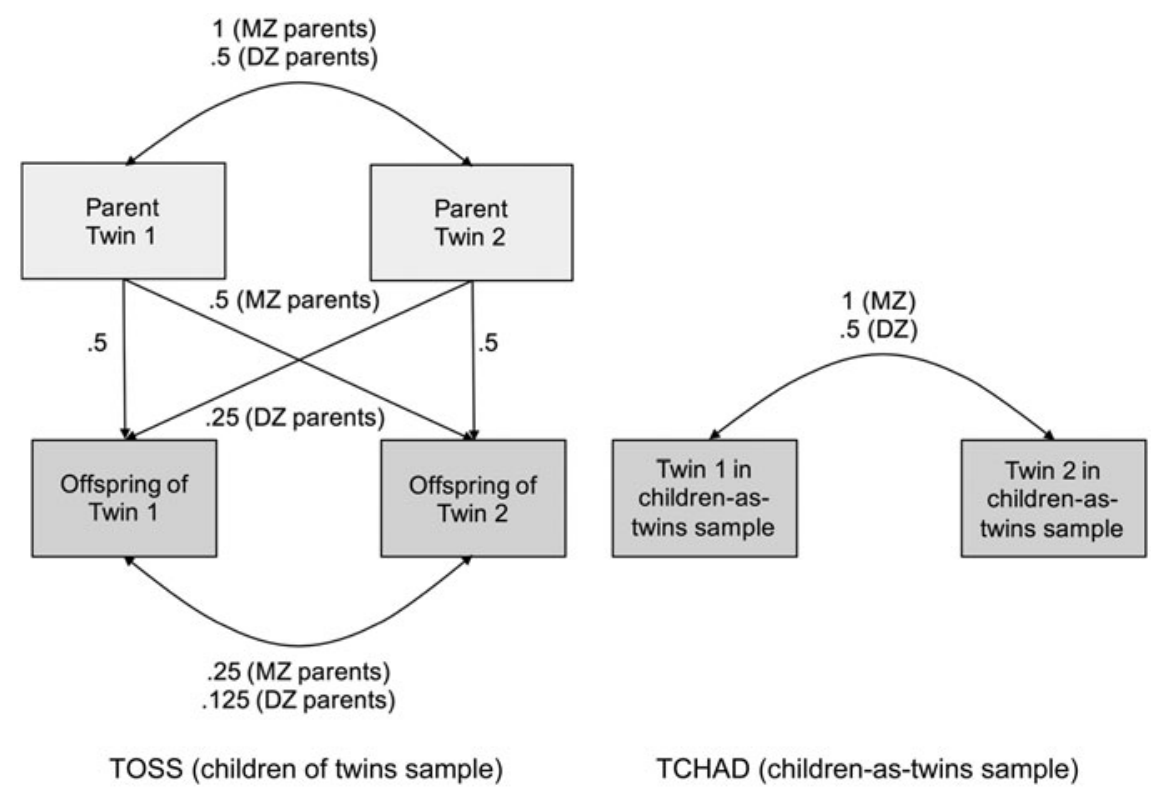

Note $-M Z=$ monozygotic $D Z=$ dizygotic

Fig. 1. Model of the genetic correlations within the Children of Twins (TOSS) and parallel children-as-twins (TCHAD) samples.
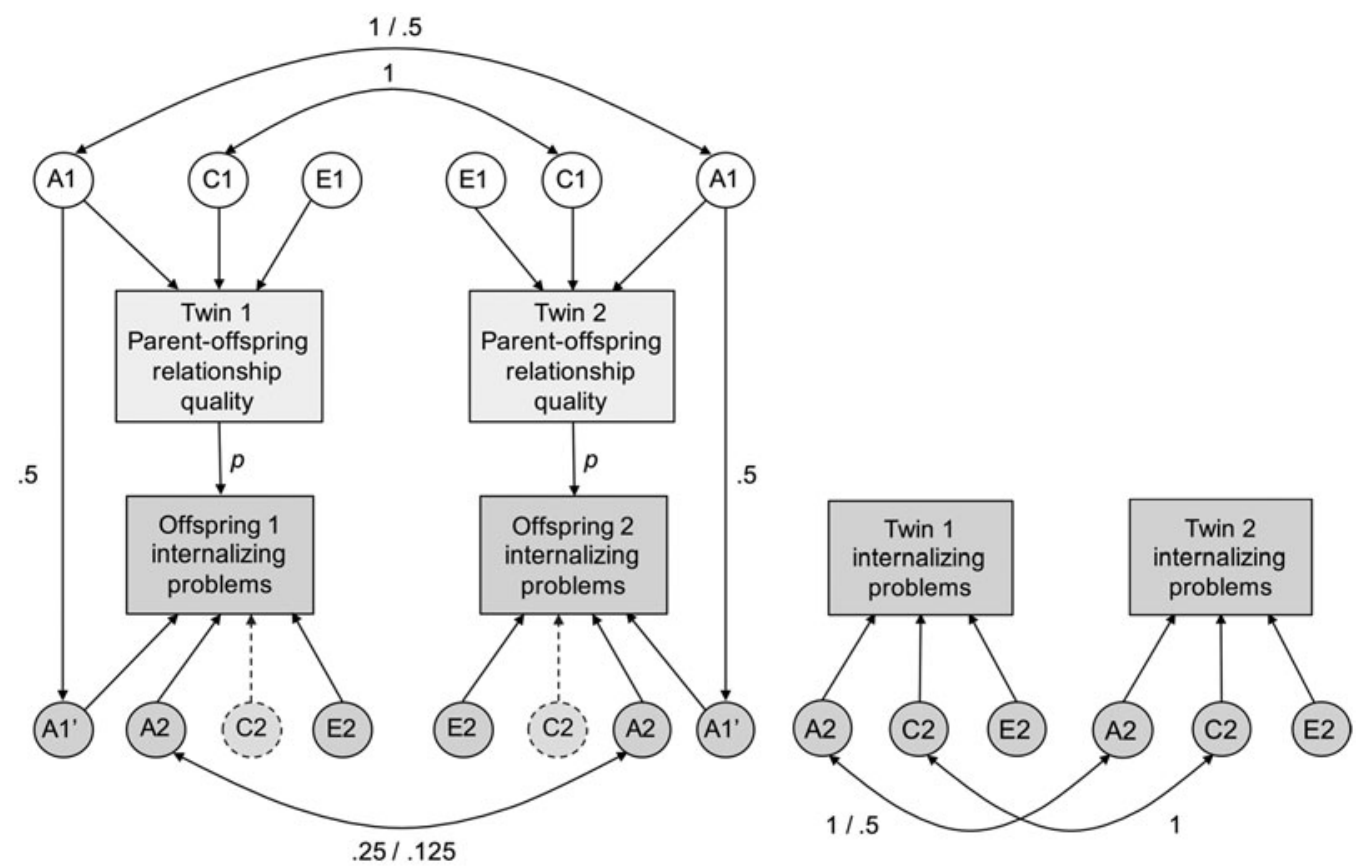

Note $-A=$ Additive genetic; $C=$ Common environmental; $E=$ Unique environmental;

Aetiological correlation values given as: $M Z / D Z$;

C2 parameter estimated from children-as-twins data only

Fig. 2. Children-of-Twins model for parent-offspring relationship quality and offspring internalizing problems, incorporating internalizing problems data from children-as-twins sample. 
Table 1. Correlations between parent-reported parent-offspring relationship quality and offspring self-reported internalizing problems in monozygotic and dizygotic twin-parent families (TOSS) and child-as-twin families (TCHAD)

\begin{tabular}{|c|c|c|c|c|}
\hline & \multicolumn{2}{|l|}{ TOSS } & \multicolumn{2}{|l|}{ TCHAD } \\
\hline & $\mathrm{MZ}$ & $\mathrm{DZ}$ & $\mathrm{MZ}$ & $\mathrm{DZ}$ \\
\hline \multicolumn{5}{|l|}{ Parent generation } \\
\hline Twin (RQ-RQ) & 0.35 & 0.19 & & \\
\hline $95 \% C I$ & $0.25-0.44$ & $0.11-0.27$ & & \\
\hline \multicolumn{5}{|l|}{ Child generation } \\
\hline Cousin (IP-IP) & 0.16 & 0.10 & & \\
\hline $95 \% C I$ & $0.06-0.26$ & $0.00-0.19$ & & \\
\hline Twin (IP-IP) & & & 0.55 & 0.27 \\
\hline $95 \% C I$ & & & $0.49-0.60$ & $0.25-0.33$ \\
\hline \multicolumn{5}{|l|}{ Intergenerational } \\
\hline Parent-offspring (RQ-IP) & 0.21 & 0.21 & & \\
\hline $95 \% C I$ & $0.16-0.26$ & $0.16-0.26$ & & \\
\hline Avuncular (RQ-IP) & 0.07 & 0.11 & & \\
\hline $95 \% C I$ & $0.00-0.15$ & $0.05-0.17$ & & \\
\hline
\end{tabular}

Bold typeface signifies statistical significance; all confidence intervals should be italicized. RQ, parent-offspring relationship quality; IP, internalizing problems.

Parent-offspring correlations are constrained to be equal across twin order and zygosity, in line with theoretical expectations that they will not differ significantly (the validity of this assumption was affirmed by constraining the saturated model and observing no significant decrement of model fit).

v. 0.11), indicating a negligible role for passive genetic transmission effects in underpinning this association.

The results of the model-fitting procedure are presented in Table 2. First, we compared the fit of the full CoT model to the saturated phenotypic model, in order to test the basic assumptions of the model. Subsequent model comparisons were between the full CoT model and a series of reduced sub-models. All submodels were nested in the larger full model, meaning that model fit could be compared using a $\chi^{2}$ difference test of their $-2 \mathrm{LL}$ values. Sub-models $1-3$ tested the significance of shared environmental $(C)$ parameters in both generations (independently and then together), as these were either non-significant or estimated at zero in the full model. None of these models resulted in a decrement of fit, so the most parsimonious (model 3) was used as a basis for further constraints. We ran models 4-6 to investigate the characteristics of the association between parent-offspring relationship quality and offspring internalizing problems. Model 4, in which the $A 1^{\prime}$ genetic transmission parameter was fixed to zero, provided the best fit for the data. This indicates that passive genetic effects did not contribute significantly to the association. In contrast, both model 5 (in which the genetic transmission path was reinstated and social transmission was fixed to zero) and model 6 (which tested the overall significance of the intergenerational association) resulted in a significantly poorer fit to the data. Below, we present and describe the results of model 4 (the best-fitting model overall) alongside the full model for comparison.

Figure 3 presents the estimates from the full (panel A) and best-fitting models (panel B) of parent-reported parent-offspring relationship quality and offspring selfreported internalizing problems. The 95\% confidence intervals (CIs) are presented below each estimate in italicized typeface. All non-significant parameters in the full model are dropped (as described above) in the best-fitting model, leaving the final estimate of the effects of social transmission at 0.21 . The heritability of parent-offspring relationship quality is estimated at 0.36 , and the heritability of offspring internalizing problems at 0.55. Shared environmental influences were not significant in either generation, with non-shared environmental influences explaining the remaining variance in parent-offspring relationship quality (0.64) and offspring internalizing problems (0.41), respectively.

\section{Discussion}

Associations between measures of parenting and child outcomes are not straightforward to interpret, due to the inter-relatedness of genetic and environmental influences within the home environment (Collins et al. 2000; Rutter, 2004; Horwitz \& Neiderhiser, 2015). In the current study, we used a CoT design, to show that an intergenerational, passive genetic pathway does not explain a significant proportion of the 
Table 2. Fit indices from model-fitting of parent-reported parent-offspring relationship quality and offspring self-reported internalizing problems

\begin{tabular}{|c|c|c|c|c|c|c|c|}
\hline & ep & $-2 \mathrm{LL}$ & df & AIC & $\Delta \mathrm{LL}$ & $\Delta \mathrm{df}$ & $p$ \\
\hline \multicolumn{8}{|l|}{ Model } \\
\hline Saturated model & 38 & 15574.94 & 5586 & 4402.94 & - & - & - \\
\hline Full CoT model & 11 & 15608.30 & 5613 & 4382.30 & 33.35 & 27 & 0.19 \\
\hline \multicolumn{8}{|l|}{ Sub-models } \\
\hline 1. Drop C1 & 10 & 15608.61 & 5614 & 4380.61 & 0.32 & 1 & 0.57 \\
\hline 2. Drop C2 & 10 & 15608.30 & 5614 & 4380.30 & 0.00 & 1 & 1 \\
\hline 3. Drop C & 9 & 15608.61 & 5615 & 4378.61 & 0.32 & 2 & 0.85 \\
\hline 4. Direct transmission only (drop $C ; A 1^{\prime}$ ) & 8 & 15609.70 & 5616 & 4377.70 & 1.40 & 3 & 0.70 \\
\hline 5. Genetic transmission only (drop $C ; p)$ & 8 & 15620.39 & 5616 & 4388.39 & 12.09 & 3 & 0.01 \\
\hline 6. No intergenerational association (drop $\left.C ; p ; A 1^{\prime}\right)$ & 7 & 15681.53 & 5617 & 4447.53 & 73.24 & 4 & $<0.001$ \\
\hline
\end{tabular}

ep, estimated parameters; -2LL, log likelihood; df, degrees of freedom; AIC, Akaike's Information Criterion.

Best-fitting model in bold typeface; nested models compared with full model using formal test of change in -2LL value; CoT refers to full Children-of-Twins model incorporating child-as-twin data.

A

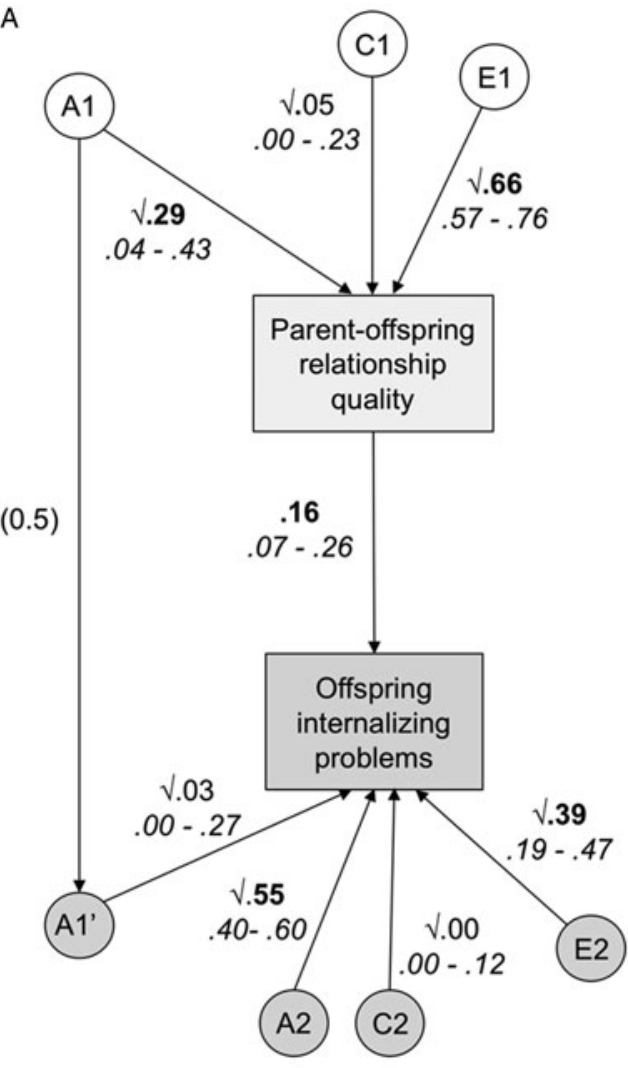

B

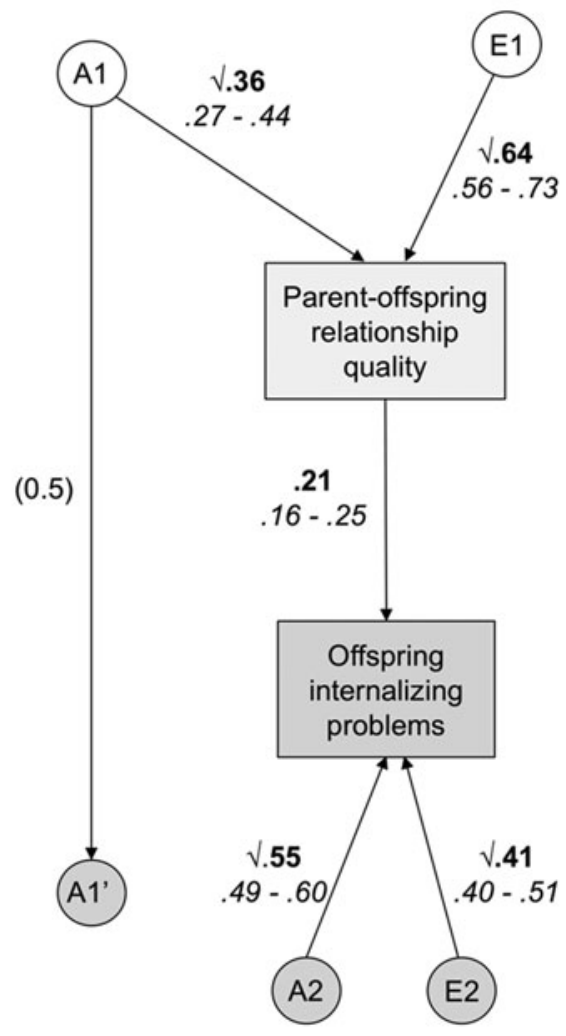

Note $-A=$ Additive genetic; $C=$ Common environmental; $E=$ Unique environmental;

Fig. 3. Path diagram showing parameter estimates from the full (A) and best-fitting reduced (B) model of parent-reported parent-offspring relationship quality and offspring self-reported internalizing problems.

association between parent-offspring relationship quality and offspring internalizing. Instead, the best-fitting model involved only social transmission effects. Although the direction and precise nature of the social effects operating to underpin the intergenerational association cannot be determined using this study design, these results add to a growing body of genetically informed parenting research that has implications for the study and treatment of childhood internalizing problems. 


\section{Parent-offspring relationship quality and offspring internalizing problems not related via passive genetic effects}

The primary goal of this study was to test whether parent-offspring relationship quality, as reported on by parents, was related to offspring self-reported internalizing problems via passive genetic transmission. Evidence of such a process would mean that the same genetic factors that influenced parenting in one generation also influenced internalizing problems in the other. Our model-fitting results strongly suggested that this is not the case within our CoT sample: passive genetic effects did not explain intergenerational association to any significant extent.

Though limited in number, previous studies investigating the aetiology of intergenerational associations between parenting phenotypes and internalizing problems have produced similar findings (Lynch et al. 2006; Narusyte et al. 2008; Schermerhorn et al. 2011; McAdams et al. 2014, 2017; Horwitz et al. 2015). To further contextualize this finding, it is worth emphasizing that our sample did meet three important theoretical pre-conditions for passive genetic transmission to be a plausible mechanism. First, consistent with findings from previous studies (see reviews by Kendler \& Baker, 2007; Klahr \& Burt, 2014), there were genetic influences on parents' perceptions of their relationship with their child. Second, similarly, adolescent children's internalizing problems were subject to genetic influence. This, too, is in line with the existing evidence base (Rice et al. 2002; Rapee et al. 2009; Polderman et al. 2015). Finally, we saw evidence of a significant intergenerational association between the measures. The magnitude of this association (0.21) was in line with results from previous meta-analyses of intergenerational associations between parenting and child internalizing problems more generally (McLeod et al. 2007; Yap \& Jorm, 2015; Möller et al. 2016). In this context, our finding of no role for a passive genetic mechanism appears unlikely to be related to any unusual characteristics of either the sample or the measures used in our study.

\section{Evidence for the importance of social interactions; bidirectional effects possible}

With no evidence of passive genetic transmission in the association between parent-offspring relationship quality and offspring internalizing problems, a social mechanism was found to be the best explanation of this relationship within our models. Significantly, this was the first CoT study to investigate the nature of this kind of association using a broad measure of the parent-offspring relationship, rather than specific parenting behaviours, such as discipline or overinvolvement. Our finding seems to reduce the possibility that the specificity of the parenting phenotypes used in earlier studies precluded the detection of passive genetic confounding that was present in the broader parent-child relationship. Instead, the importance of social interactions for producing such associations seems relatively unequivocal from studies using this design. However, there are several plausible alternatives for the precise mechanisms involved.

The first possible mechanism involves parent-tochild effects, in which poor quality parent-offspring interactions act as an environmental risk factor for children to develop internalizing problems. Evidence of such a mechanism has been shown for some parenting phenotypes and child behavioural outcomes (Asbury et al. 2003; Burt et al. 2005; Bornovalova et al. 2014) though it is notable that there is some debate, prompted by limited evidence for sustained shared environmental influences on behaviour later in development and into adulthood, about the enduring effects of parenting as experienced similarly by siblings (summarized in Burt, 2014) other than as a result of extremely maladaptive parental behaviours (e.g. abuse and neglect; Norman et al. 2012).

A second possible mechanism involves the reverse direction of causation, with child internalizing problems influencing parent-offspring relationship quality. Within this model of child-to-parent effects, it is important to note that, with parents and children sharing only $\approx 50 \%$ of segregating genes, child genes may still play a role in influencing the parent-offspring relationship (via their influence on the child's internalizing problems). Indeed, evidence from a range of study designs has demonstrated the role of children's genetically influenced behaviour in evoking parenting responses (Avinun \& Knafo, 2014; Klahr \& Burt, 2014). Given the strength of this previous evidence and the consistency of this mechanism with longstanding 'bidirectional effects' models of family functioning (Bell, 1979; Bronfenbrenner, 1986), it seems likely that some genetically influenced child-driven effects underpin this association. Although the extent of this evocative mode of gene-environment correlation cannot be estimated in this study, we can conclude that any child genes influencing parent-offspring relationship quality in this way are not the same as those genes influencing the relationship via the parents' behaviour; otherwise, their effect would have resulted in significant direct genetic transmission in the models.

The possible influence of children's genes in the social transmission path in the CoT model is the reason that we avoid referring to it with any variant of the term 'environmental', which could reasonably be assumed to mean 'entirely non-genetic'. Instead, we label this mode of transmission with a term that emphasizes what is common to the two mechanisms 
outlined above: namely, a requirement for social interaction. Evidence from adoption studies is broadly supportive of this, with small or no genetic transmission effects found between birth parent characteristics and their adopted-away children's emotional outcomes (Kerr et al. 2013; McAdams et al. 2015). Adoption designs offer a strong and direct test of the relative importance of parents' provision of genes $v$. their provision of environments, but are often limited in scale and representativeness. In addition to CoT samples, novel designs leveraging differences in family types created by assisted conception (Harold et al. 2011) or divorce and remarriage (Kendler et al. 2015, 2016) offer promise of progress in this area.

Ruling out confounding by passive genetic transmission, quantifying the importance of social interactions and understanding the direction of effects within associations between parenting and child psychopathology are important for appropriately targeting family-based interventions. To rigourously define targets for interventions within the family environment, experimental work must be coordinated with findings from studies that are designed to isolate and delineate specific mechanisms and risk processes (Howe et al. 2010; Brody et al. 2013). Recent evidence suggests that findings from molecular genetic studies are becoming increasingly applicable in this regard (Brody et al. 2015; Keers et al. 2016). As well as being important for designing effective interventions and targeting them efficiently, precisely defining mechanisms by which risk for psychopathology is mediated in families is crucial for improving our understanding of how and why problems such as depression emerge when they do. In the short term, approaches to the treatment of internalizing problems in childhood and adolescence should continue to account for links with children's family environments, which remain robust even when controlling for genetic relatedness. Evidence from the current study suggests that the social features of the parent-child relationship should be considered as part of the clinical picture for internalizing problems well into adolescence.

\section{Limitations}

The limitations and main assumptions of the CoT approach have been discussed in detail elsewhere (D'Onofrio et al. 2003; McAdams et al. 2014). The CoT formulation of the equal environments assumption that underpins twin research in general is that offspring in MZ families have no more avuncular contact (time spent with aunts/uncles) than offspring in DZ families. Where studied, this assumption has been shown to hold adequately to support these analyses (Koenig et al. 2010).
A specific issue in the current study concerns the nature of parents' reporting on the quality of the parent-offspring relationship, which may only partly reflect their child's subjective experience (Hannigan et al. 2016a). To the extent that parents' own internalizing problems influenced their reporting, and were influenced by the same genes as child internalizing problems, this would inflate the estimate of genetic transmission in the model. However, two factors mitigate this limitation. The first is that previous studies have detected no significant genetic transmission when examining parent-adolescent associations for anxiety (Eley et al. 2015) or depression (McAdams et al. 2015). Secondly, by using offspring self-reports of their internalizing problems, we avoid the potential for spurious genetic overlap caused by a genetically influenced rater effect.

A final limitation concerns the decision not to separate maternal and paternal reports of the parent-offspring relationship. Some previous work has indicated that different modes of mechanisms may underpin intergenerational transmission via maternal and paternal behaviours (Narusyte et al. 2011). However, we opted not to split our sample on this basis for due to power concerns, and a lack of a strong rationale for expecting such differences. Nonetheless, other studies could investigate this possibility in future.

\section{Conclusion}

The findings from this study add to a growing body of literature highlighting the importance of social transmission in associations between parenting-related phenotypes and offspring internalizing problems. Although other designs are required to quantify the extent of bidirectionality in this phenotypic transmission, two clear conclusions can be drawn from the results of these analyses. First, shared genes do not appear to contribute to overlap between the quality of the parent-offspring relationship and offspring internalizing problems. Second, the intergenerational transmission that does occur is thus contingent on parents' and children's exposure to one another. Both of these conclusions are non-trivial and have implications for developmental scientists and clinicians alike. Developing an appropriately nuanced understanding of the interactions and behavioural cycles that produce and maintain the associations between parenting interactions and child outcomes relies upon the continued investigation of potential sources of genetic confounding.

\section{Acknowledgements}

The Twin and Offspring Study in Sweden was supported by Grant R01MH54610 from the National Institute of 
Mental Health. The TCHAD study is funded by the Swedish Council for Working Life and Social Research (project 2004-0383) and the Swedish Research Council (2004-1415). This study presents independent research part-funded by the National Institute for Health Research (NIHR) Biomedical Research Centre at South London and Maudsley NHS Foundation Trust and King's College London. The views expressed are those of the author(s) and not necessarily those of the NHS, the NIHR or the Department of Health. LJH is supported by a $1+3$ Ph.D. studentship from the UK Economic and Social Research Council (ESRC). TAM is supported by a Sir Henry Dale Fellowship, jointly funded by the Wellcome Trust and the Royal Society (107706/Z/ $15 / Z)$. This work was completed the support of The Swedish Foundation for International Cooperation in Research and Higher Education. The authors would like to thank the participants of both the TOSS and TCHAD studies for contributing their data for this work. The views expressed here are not those of the National Institutes of Health (NIH).

\section{Declaration of Interest}

None.

\section{References}

Achenbach TM (1991). Integrative Guide for the 1991 CBCL/418, YSR, and TRF Profiles. Department of Psychiatry, University of Vermont: Burlington, VT.

Achenbach TM, Edelbrock CS (1983). Manual for the Child Behavior Checklist: And Revised Child Behavior Profile. University of Vermont, Department of Psychiatry: Burlington, VT.

Asbury K, Dunn J, Pike A, Plomin R (2003). Nonshared environmental influences on individual differences in early behavioral development: a monozygotic twin differences study. Child Development 74, 933-943.

Avinun R, Knafo A (2014). Parenting as a reaction evoked by children's genotype: a meta-analysis of children-as-twins studies. Personality and Social Psychology Review 18, 87-102. Bell RQ (1979). Parent, child, and reciprocal influences. American Psychologist 34, 821-826.

Belsky J (1984). The determinants of parenting: a process model. Child Development 55, 83-96.

Bornovalova MA, Cummings JR, Hunt E, Blazei R, Malone SM, Iacono WG (2014). Understanding the relative contributions of direct environmental effects and passive genotype-environment correlations in the association between familial risk factors and child disruptive behavior disorders. Psychological Medicine 44, 831-844.

Braungart J, Fulker D, Plomin R (1992). Genetic mediation of the home environment during infancy: a sibling adoption study of the HOME. Developmental Psychology 28, 1048-1055.

Brody GH, Beach SRH, Hill KG, Howe GW, Prado G, Fullerton SM (2013). Using genetically informed, randomized prevention trials to test etiological hypotheses about child and adolescent drug use and psychopathology. American Journal of Public Health 103, S19-S24.

Brody GH, Yu T, Beach SRH (2015). A differential susceptibility analysis reveals the 'who and how' about adolescents' responses to preventive interventions: tests of first- and second-generation gene $\times$ intervention hypotheses. Development and Psychopathology 27, 37-49.

Bronfenbrenner U (1986). Ecology of the family as a context for human development: research perspectives. Developmental Psychology 22, 723-742.

Burt SA (2014). Research review: the shared environment as a key source of variability in child and adolescent psychopathology. Journal of Child Psychology and Psychiatry 55, 304-312.

Burt SA, McGue M, Krueger RF, Iacono WG (2005). How are parent-child conflict and childhood externalizing symptoms related over time? Results from a genetically informative cross-lagged study. Development and Psychopathology 17, 145-165.

Collins WAW, Maccoby EEE, Steinberg L, Hetherington EME, Bornstein MH (2000). Contemporary research on parenting: the case for nature and nurture. American Psychologist 55, 218-232.

Connell AM, Goodman SH (2002). The association between psychopathology in fathers versus mothers and children's internalizing and externalizing behavior problems: a meta-analysis. Psychological Bulletin 128, 746-773.

Cox DR, Box GEP, Cox DR (1964). An analysis of transformations. Journal of the Royal Statistical Society. Series $B$ (Methodological) 26, 211-252.

Critchley CR, Sanson AV (2006). Is parent disciplinary behavior enduring or situational? A multilevel modeling investigation of individual and contextual influences on power assertive and inductive reasoning behaviors. Journal of Applied Developmental Psychology 27, 370-388.

Darling N, Steinberg L (1993). Parenting style as context: an integrative model. Psychological Bulletin 113, 487-496.

D'Onofrio B, Turkheimer EN, Eaves LJ, Corey LA, Berg K, Solaas MH, Emery RE (2003). The role of the children of twins design in elucidating causal relations between parent characteristics and child outcomes. Journal of Child Psychology and Psychiatry 44, 1130-1144.

Eley TC, McAdams TA, Rijsdijk FV, Lichtenstein P, Narusyte J, Reiss D, Spotts EL, Ganiban JM, Neiderhiser JM (2015). The intergenerational transmission of anxiety: a children-of-twins study. American Journal of Psychiatry 172, 630-637.

Goodman SH, Rouse MH, Connell AM, Broth MR, Hall CM, Heyward D (2011). Maternal depression and child psychopathology: a meta-analytic review. Clinical Child and Family Psychology Review 14, 1-27.

Hannigan LJ, McAdams TA, Plomin R, Eley TC (2016a). Etiological influences on perceptions of parenting: a longitudinal, multi-informant twin study. Springer US Journal of Youth and Adolescence 45, 2387-2405.

Hannigan LJ, McAdams TA, Plomin R, Eley TC (2016b). Parent- and child-driven effects during the transition to adolescence: a longitudinal, genetic analysis of the home environment. Developmental Science 1-16, In press.

Harold GT, Rice F, Hay DF, Boivin J, Van den Bree M, Thapar A (2011). Familial transmission of depression and 
antisocial behaviour symptoms: disentangling the contribution of inherited and environmental factors and testing the mediating role of parenting. Psychological Medicine 41, 1175-1185.

Harrington R, Fudge H, Rutter M, Pickles A, Hill J (1990). Adult outcomes of childhood and adolescent depression. I. Psychiatric status. Archives of General Psychiatry 47, 465-473.

Hetherington E, Clingempeel W (1992). Coping with marital transitions: a family systems perspective. Monographs of the Society for Research in Child Development 57, 1-14.

Horwitz BN, Ganiban J, Spotts EL, Reiss D, Marceau K, Narusyte J, Ganiban J, Spotts EL, Reiss D, Lichtenstein P, Neiderhiser JM (2015). Parental criticism is an environmental influence on adolescent somatic symptoms. Journal of Family Psychology 29, 283-289.

Horwitz BN, Neiderhiser JM (2015). Gene-environment interplay, interpersonal relationships, and development: a volume introduction. In Gene-Environment Interplay in Interpersonal Relationships across the Lifespan (ed. B. N. Horwitz, J. M. Neiderhiser), pp. 1-12. Springer: New York, NY.

Howe GW, Beach SRH, Brody GH (2010). Microtrial methods for translating gene-environment dynamics into preventive interventions. Prevention Science 11, 343-354.

Hudson JL, Rapee RM (2001). Parent-child interactions and anxiety disorders: an observational study. Behaviour Research and Therapy 39, 1411-1427.

Keers R, Coleman JRI, Lester KJ, Roberts S, Breen G, Thastum M, Bögels S, Schneider S, Heiervang E, MeiserStedman R, Nauta M, Creswell C, Thirlwall K, Rapee RM, Hudson JL, Lewis C, Plomin R, Eley TC (2016). A genome-wide test of the differential susceptibility hypothesis reveals a genetic predictor of differential response to psychological treatments for child anxiety disorders. Psychotherapy and Psychosomatics 85, 146-158.

Kendler KS, Baker JH (2007). Genetic influences on measures of the environment: a systematic review. Psychological Medicine 37, 615-626.

Kendler KS, Ohlsson H, Edwards AC, Lichtenstein P, Sundquist K, Sundquist J (2016). A novel sibling-based design to quantify genetic and shared environmental effects: application to drug abuse, alcohol use disorder and criminal behavior. Psychological Medicine 46, 1639-1650.

Kendler KS, Ohlsson H, Sundquist J, Sundquist K (2015). Triparental families: a new genetic-epidemiological design applied to drug abuse, alcohol use disorders, and criminal behavior in a Swedish national sample. American Journal of Psychiatry 172, 553-560.

Kendler KS, Sham PC, MacLean CJ (1997). The determinants of parenting: an epidemiological, multi-informant, retrospective study. Psychological Medicine 27, 549-563.

Kerr DCR, Leve LD, Harold GT, Natsuaki MN, Neiderhiser JM, Shaw DS, Reiss D (2013). Influences of biological and adoptive mothers' depression and antisocial behavior on adoptees' early behavior trajectories. Journal of Abnormal Child Psychology 41, 723-734.

Kessler RC, Berglund P, Demler O, Jin R, Merikangas KR, Walters EE (2005). Lifetime prevalence and age-of-onset distributions of DSM-IV disorders in the national comorbidity survey replication. Archives of General Psychiatry 62, 593.

Kiff CJ, Lengua LJ, Zalewski M (2011). Nature and nurturing: parenting in the context of child temperament. Clinical Child and Family Psychology Review 14, 251-301.

Kim-Cohen J, Caspi A, Moffitt TE, Harrington H, Milne BJ, Poulton R (2003). Prior juvenile diagnoses in adults with mental disorder: developmental follow-back of a prospective-longitudinal cohort. Archives of General Psychiatry 60, 709-717.

Klahr AM, Burt SA (2014). Elucidating the etiology of individual differences in parenting: a meta-analysis of behavioral genetic research. Psychological Bulletin 140, 544586.

Koenig LB, Jacob T, Haber JR, Xian H (2010). Testing the equal environments assumption in the children of twins design. Behavior Genetics 40, 533-541.

Kovacs M, Devlin B (1998). Internalizing disorders in childhood. Journal of Child Psychology and Psychiatry and Allied Disciplines 39, 47-63.

Laskey BJ, Cartwright-Hatton S (2009). Parental discipline behaviours and beliefs about their child: associations with child internalizing and mediation relationships. Child: Care, Health and Development 35, 717-727.

Lichtenstein P, Tuvblad C, Larsson H, Carlström E (2007). The Swedish twin study of child and adolescent development: the TCHAD-study. Twin Research and Human Genetics 10, 67-73.

Ludeke S, Johnson W, McGue M, Iacono WG (2013). Genetic amplification and the individualization of the parent-child relationship across adolescence. Psychological Medicine 43, 413-422.

Lynch SK, Turkheimer EN, D'Onofrio B, Mendle J, Emery RE, Slutske WS, Martin N (2006). A genetically informed study of the association between harsh punishment and offspring behavioral problems. Journal of Family Psychology 20, 190-198.

Marceau K, Horwitz BN, Narusyte J, Ganiban JM, Spotts EL, Reiss D, Neiderhiser JM (2013). Gene-environment correlation underlying the association between parental negativity and adolescent externalizing problems. Child Development 84, 2031-2046.

McAdams TA, Neiderhiser JM, Rijsdijk FVFV, Narusyte J, Lichtenstein P, Eley TCT (2014). Accounting for genetic and environmental confounds in associations between parent and child characteristics: a systematic review of children-of-twins studies. Psychological Bulletin 140, 1138-1173.

McAdams TA, Rijsdijk FV, Narusyte J, Ganiban JM, Reiss D, Spotts E, Neiderhiser JM, Lichtenstein P, Eley TC (2017). Associations between the parent-child relationship and adolescent self-worth: a genetically informed study of twin parents and their adolescent children. Journal of Child Psychology and Psychiatry 58, 46-54.

McAdams TA, Rijsdijk FV, Neiderhiser JM, Narusyte J, Shaw DS, Natsuaki MN, Spotts EL, Ganiban JM, Reiss D, Leve LD, Lichtenstein P, Eley TC (2015). The relationship between parental depressive symptoms and offspring psychopathology: evidence from a children-of-twins study and an adoption study. Psychological Medicine 45, 2583-2594. 
McKee L, Roland E, Coffelt N, Olson AL, Forehand R, Massari C, Jones D, Gaffney CA, Zens MS (2007). Harsh discipline and child problem behaviors: the roles of positive parenting and gender. Journal of Family Violence 22, 187-196.

McLeod BD, Weisz JR, Wood JJ (2007). Examining the association between parenting and childhood depression: a meta-analysis. Clinical Psychology Review 27, 986-1003.

Metsäpelto RL, Pulkkinen L, Poikkeus AM (2001). A search for parenting style: a cross-situational analysis of parental behavior. Genetic, Social, and General Psychology Monographs 127, 169-192.

Miller PC, Shim JE, Holden GW (1998). Immediate contextual influences on maternal behavior: environmental affordances and demands. Journal of Environmental Psychology 18, 387-398.

Möller EL, Nikolić M, Majdandžić M, Bögels SM (2016). Associations between maternal and paternal parenting behaviors, anxiety and its precursors in early childhood: a meta-analysis. Clinical Psychology Review 45, 17-33.

Narusyte J, Neiderhiser JM, Andershed A-K, D'Onofrio B, Reiss D, Spotts EL, Ganiban JM, Lichtenstein P (2011). Parental criticism and externalizing behavior problems in adolescents: the role of environment and genotype-environment correlation. Journal of Abnormal Psychology 120, 365-376.

Narusyte J, Neiderhiser JM, D'Onofrio B, Reiss D, Spotts EL, Ganiban JM, Lichtenstein P (2008). Testing different types of genotype-environment correlation: an extended children-oftwins model. Developmental Psychology 44, 1591-1603.

Neiderhiser JM (2001). Understanding the roles of genome and envirome: methods in genetic epidemiology. The British Journal of Psychiatry 178, 12s-17s.

Neiderhiser JM, Lichtenstein P (2008). The twin and offspring study in Sweden: advancing our understanding of genotype-environment interplay by studying twins and their families the twin and offspring study in Sweden. Acta Psychologica Sinica 40, 1116-1123.

Neiderhiser JM, Reiss D, Lichtenstein P, Spotts EL, Ganiban JM (2007). Father-adolescent relationships and the role of genotype-environment correlation. Journal of Family Psychology 21, 560-571.

Neiderhiser JM, Reiss D, Pedersen NL, Lichtenstein P, Spotts EL, Hansson K, Cederblad M, Ellhammer O (2004). Genetic and environmental influences on mothering of adolescents: a comparison of two samples. Developmental Psychology 40, 335-351.

Norman RE, Byambaa M, De R, Butchart A, Scott J, Vos T (2012). The long-term health consequences of child physical abuse, emotional abuse, and neglect: a systematic review and meta-analysis. PLoS Medicine 9, e1001349.

Plomin R, Bergeman CS (1991). The nature of nurture: genetic influence on 'environmental' measures. Behavioral and Brain Sciences 14, 373-386.

Plomin R, DeFries JC, Loehlin JC (1977). Genotypeenvironment interaction and correlation in the analysis of human behavior. Psychological Bulletin 84, 309-322.

Plomin R, Loehlin JC, DeFries JC (1985). Genetic and environmental components of 'environmental' influences. Developmental Psychology 21, 391-402.
Plomin R, McClearn G, Pedersen NL, Nesselroade J, Bergeman CS (1989). Genetic influence on adults' ratings of their current family environment. ... Marriage and the Family 51, 791-803.

Polderman TJC, Benyamin B, de Leeuw CA, Sullivan PF, van Bochoven A, Visscher PM, Posthuma D (2015). Meta-analysis of the heritability of human traits based on fifty years of twin studies. Nature Publishing Group Nature Genetics 47, 702-709.

Rapee RM, Schniering CA, Hudson JL (2009). Anxiety disorders during childhood and adolescence: origins and treatment. Annual Review of Clinical Psychology 5, 311-341.

Reidler EB, Swenson LLP (2012). Discrepancies between youth and mothers' perceptions of their mother-child relationship quality and self-disclosure: implications for youth- and mother-reported youth adjustment. Journal of Youth and Adolescence 41, 1151-1167.

Rice F, Harold GT, Thapar A (2002). The genetic aetiology of childhood depression: a review. Journal of Child Psychology and Psychiatry and Allied Disciplines 43, 65-79.

Rijsdijk FV, Sham PC (2002). Analytic approaches to twin data using structural equation models. Briefings in Bioinformatics 3, 119-133.

Roza SJ, Hofstra MB, Van Der Ende J, Verhulst FC (2003). Stable prediction of mood and anxiety disorders based on behavioral and emotional problems in childhood: a 14-year follow-up during childhood, adolescence, and young adulthood. American Journal of Psychiatry 160, 2116-2121.

Rutter M (2004). Pathways of genetic influences on psychopathology. European Review 12, 19-33.

Rutter M, Kim-Cohen J, Maughan B (2006). Continuities and discontinuities in psychopathology between childhood and adult life. Journal of Child Psychology and Psychiatry and Allied Disciplines 47, 276-295.

Sakia RM (1992). The box-cox transformation technique: a review. Journal of the Royal Statistical Society. Series D (The Statistician) 47, 169-178.

Schermerhorn A, D'Onofrio B, Turkheimer EN, Ganiban JM, Spotts EL, Lichtenstein P, Reiss D, Neiderhiser JM (2011). A genetically informed study of associations between family functioning and child psychosocial adjustment. Developmental Psychology 47, 707-725.

Silberg JL, Maes H, Eaves LJ (2010). Genetic and environmental influences on the transmission of parental depression to children's depression and conduct disturbance: an extended children of twins study. Journal of Child Psychology and Psychiatry 51, 734-744.

Singh A, D'Onofrio B (2011). Parental depression and offspring psychopathology: a children of twins study. Psychological Medicine 41, 1385-1395.

Steinberg L (2000). The family at adolescence: transition and transformation. Journal of Adolescent Health 27, 170-178.

Yap MBH, Jorm A (2015). Parental factors associated with childhood anxiety, depression, and internalizing problems: a systematic review and meta-analysis. Elsevier Journal of Affective Disorders 175, 424-440. 